\title{
Vascular endothelial growth factor (VEGF)-C - a potent risk factor in children diagnosed with stadium 4 neuroblastoma
}

\author{
Michal Nowicki',2, Aneta Konwerska ${ }^{2}$, Danuta Ostalska-Nowicka ${ }^{3}$, \\ Katarzyna Derwich1, Bogdan Miskowiak ${ }^{2,4}$, Beata Kondraciuk ${ }^{2}$, Dariusz Samulak ${ }^{5}$ \\ and Martin Witt6
}

Departments of: ${ }^{1}$ Paediatric Oncology, Haematology and Transplantology, ${ }^{2}$ Histology and Embryology, ${ }^{3}$ Paediatric Cardiology and Nephrology, ${ }^{4}$ Optometry and Biology of the Visual System, ${ }^{5}$ Surgical Gynaecology Poznan University of Medical Sciences, Poland and ${ }^{6}$ Anatomy Department, Technical University in Dresden, Germany

\begin{abstract}
To evaluate the immunohistochemical expression of VEGF-C, CD34 and VEGFR-2 in cancer tissue of children diagnosed with stadium 4 neuroblastoma (NB) and correlate their presence with the survival rate of children diagnosed with that stage of the disease. Eighteen children assigned to stadium 4 composed the study group. Fourteen patients (allocated to stadium 3) formed a control group. VEGF-C, CD34 and VEGFR-2 expressions were evaluated by immunohistochemical assay. Consecutive slides incubated with anti-CD34 and anti-VEGFR-2 antibodies revealed that the two markers were colocalized within endothelial layer of the blood vessels. On the other hand, VEGF-C was expressed exclusively in tumour cells. As demonstrated by Fisher's exact test, the risk of NB treatment failure (progression or relapse) as well as tumour related death, when all the patients were considered, was found to be significant in VEGF-C positive patients. VEGF-C expression in NB constitutes a potent risk factor and may direct future anti-angiogenic treatment strategy. The proximity of VEGF$\mathrm{C}$ and CD34/VEGFR-2 of NB could be the equivalent of a potentially interesting VEGF-C fashion involving a tumour cell invasion into the blood vessels in an early phase of metastases promoting.
\end{abstract}

Key words: VEGF-C, VEGFR-2, CD34, neuroblastoma, metastases

\section{Introduction}

The vascular endothelium represents a dynamic structure on the border between circulating blood and the surrounding tissue [1]. Terminally differentiated, mature endothelial cells are regarded to have a low proliferative potential. Thus, endothelial repair and angiogenesis, including neovascularization, evidently need the support of other angiogenic cells. These are derived from the bone marrow and have been termed endothelial progenitor cells (EPCs) [1-6]. They have properties of embryonal angioblasts and are characterised by expression of 3 surface markers; CD133,

Correspondence: Michal Nowicki, Dept. of Histology and Embryology, Poznan University of Medical Sciences, ul. Swiecickiego 6, 60-781 Poznan, Poland; tel.: (+4861) 8546446, fax.: (+4861) 8546440, e-mail: mnowicki@amp.edu.pl
CD34 and vascular endothelial growth factor receptor (VEGFR)-2 [2-5]. The process of intra-vascular maturation: angioblasts - early EPC - late EPC which is controlled by serum VEGF-A 165 [2-6], involves gradual loss of their progenitor properties (CD133) and start expression of endothelial markers like VE-cadherin, nitric oxide synthase and von Willebrand factor [1]. Late EPCs still express VEGFR-2 and CD34 but do not express CD133. In contrast, mature endothelial cells (ECs) usually do not express VEGFR-2 [7] while CD34 is first of all present in the vascular bed of lymphatic organs and all post-capillary venules [1].

Cancer expanding angiogenic blood vessels are not only crucial for maintaining the tumour growth [8] but, most likely, due to their embryonal-derived activity, they enable the passage of cancer cells through their wall (tumour cell invasion). In this way, the vascular bed seems to cooperate with stromal and tumour cells in early phase of metastases promoting. 
An adequate model in such research could be neuroblastoma (NB) - the second most common solid malignancy of childhood after brain tumours, accounting for $7-10 \%$ of all paediatric neoplasms [9]. About $40 \%$ of NBs arise in the adrenal medulla. The rest of them are located first of all in the paravertebral region of the abdomen $(25 \%)$ and posterior mediastinum $(15 \%)$.

Histologically, classic NBs are composed of small, primitive-appearing cells with dark nuclei, scant cytoplasm and poorly defined cell borders growing in solid sheets [10]. The loosely arranged stromal cells, situated among foci of small, blue and round cells, are usually fibrocystic or myxoid in nature. They are accompanied by well organised vasculature [9]. Metastases, when develop, appear early and widely [11]. They have a pronounced tendency to spread through the bloodstream and involve the liver, lungs, bone marrow and bones. The International Neuroblastoma Staging System includes following stadia: 1, 2A and 2B, 3, 4 and $4 \mathrm{~S}[10,12]$. The first one (with the localised tumour removed in toto) stadia 2A and 2B (localised tumour with incomplete gross resection but non-adherent to lymph nodes) as well as the stadium $4 \mathrm{~S}$ (localised tumour, as defined for stadia 1 and 2, with dissemination limited to skin or liver or bone marrow in children $<1$ yr) $[13,14]$ are relatively rare in clinical practice in Poland. The most common are stadium 3 (malignancy involving the surrounding lymphatic nodes) and stadium 4 (like the previous one but with distant metastases) [12].

The course of NB is extremely variable. Unfavourable prognostic factors involve the age $>1 \mathrm{yr}$, stadia 3 and 4 (except of 4S), high mitotic rate [15], diploidy, N-myc amplification [16-18], partial gain of the distal long arm of chromosome 17 [16], deletion of the distal short arm of chromosome 1 [19], high expression of telomerase and certain neuropeptide markers expression [20-23]. Similarly, the vessel density in NB correlates with tumour stage and outcome [24]. Expression of angiogenic factors such as VEGFA, VEGF-C, VEGF-D have been demonstrated in NB in vitro and in vivo suggesting their contribution to tumour progression and metastasis $[25,26]$. Interestingly, all of them can bind the same type of receptor VEGFR-2 (a kinase-insert domain receptor, $\mathrm{KDR} /$ foetal liver kinase, Flk-1). Except of being reported on EPCs, it is considered to be the major signalling receptor for VEGF-C [27] - a growing factor reported recently as a chief protein in NB lymphangiogenesis [26]. In this way VEGFR-2 appears to be not only a common factor coupling maturation of EPCs and growth of blood vessels but also an element binding the activities of VEGF-A165 and VEGF-C.

In line with the above, the present studies aimed to evaluate the immunohistochemical expression of
VEGF-C as well as the markers of late endothelial progenitor cells (CD34 and VEGFR-2) in cancer tissue of children diagnosed with stadium 4 neuroblastoma and correlate their presence with the survival rate of children diagnosed with that stage of the disease.

\section{Patients and methods}

Patients. During the period 1/1/1997 - 12/31/2006, 32 patients with NB were surgically treated and administered chemotherapy in the Department of Pediatric Oncology, Haematology and Transplantology, Poznan University of Medical Sciences in Poland. The research protocol was approved by the Ethical Commission of the University.

Eighteen children, aged $3-16$, were assigned to stadium 4 (study group), the rest (allocated to stadium 3) composed a control group (aged 3 - 17). Unfortunatelly, no children diagnosed with stadium 1 or $2 \mathrm{NB}$ was hospitalised in mentioned above time.

The treatment protocol was based on experience of Study Group of Japan for Treatment of Advanced Neuroblastoma, Tokyo, Japan [28]. According to that program, recommended by Polish Pediatric Solid Tumours Group in last 10 years, all the children who were suspected of having neuroblastoma (radiological examinations followed by serum dopamine and urine vanillylmandelic acid evaluations) were initially treated with 4-6 subsequent combinations of (1) cyclophosphamide // adriamycin // carboplatin $\left(1200 \mathrm{mg} / \mathrm{m}^{2} / / 50 \mathrm{mg} / \mathrm{m}^{2} / / 450 \mathrm{mg} / \mathrm{m}^{2}\right)$ and (2) cyclophosphamide // etoposide // cisplatin (1200 mg/m² x2 // 500 $\mathrm{mg} / \mathrm{m}^{2} / / 125 \mathrm{mg} / \mathrm{m}^{2}$ ). Such a procedure was recommended in order to improve the conditions for surgery. It must be emphasized that initial biopsy in this case was regarded that time as inappropriate. After that inductive chemotherapy, the tumour mass was surgically removed and tumour tissues were fixed in Bouin's solution for 24 hours at room temperature and subsequently embedded in paraffin.

Immunocytochemistry. In order to demonstrate the presence of VEGF-C, VEGFR-2 and CD34 in tumour cells, an indirect immunocytochemical procedure (the streptavidin-biotin complex method with the use of horseradish peroxidase, StreptABComplex/HRP) was performed using monoclonal mouse anti-human antibodies against VEGF-C (H-190; Santa Cruz Biotechnology, Heidelberg, Germany, sc-9047, diluted 1:100) and VEGFR-2 (pKo R, 34a; diluted 1:100, a kind gift from Prof. K.C. Gatter, University of Oxford, UK) [29] as well as CD34 (Santa Cruz Biotechnology, Heidelberg, Germany; sc-19587, diluted 1:100). Early EPCs and mitotic activity of cancer cells was defined by expressions of CD133 and Ki67. Their detection involved the use of rabbit and mouse antibodies against human CD133 and Ki67 respectively (H284; Santa Cruz Biotechnology, Heidelberg, Germany, sc-30220, diluted 1:50; Dako, Copenhagen, Denmark, M 7187, diluted $1: 100$ ). Heat-induced antigen demasking pre-treatment was also carried out (Target Retrieval Solution, Dako S 1699) [30,31]. The activity of endogenous peroxidase was blocked by $30 \mathrm{~min}$ preincubation in $3 \%$ hydrogen peroxide. Following incubation with the primary antibody for $24 \mathrm{~h}$ at $4^{\circ} \mathrm{C}$, the specimens were treated for $1 \mathrm{~h}$ at room temperature with biotin-conjugated goat antimouse IgG (diluted 1:300; Sigma, Munich, Germany). Subsequently, the sections were incubated with an $\mathrm{ABC}$ reagent (Vectastatin, Elite; Vector, Burlingame, CA, USA) for $45 \mathrm{~min}$ at room temperature. The activity of peroxidase was detected by the use of $0.5 \% 3,3$ '-diaminobenzidine in Tris $/ \mathrm{HCl}(\mathrm{pH}=7.6)$ containing $0.3 \%$ $\mathrm{H}_{2} \mathrm{O}_{2}$.

Negative controls were performed by using normal mouse IgG at the same concentrations as primary antibodies (Dako, Denmark, X 0931, diluted 1:100) or phosphate buffer saline (PBS). Addi- 
tionally, to further confirm VEGF-C and VEGFR-2 antibodies specificity, blocking peptides were used (VEGF mBA-165; Santa Cruz, Heidelberg, Germany, sc-4571; concentrated 10ng/ml and sVEGFR2-FC Chimera; RDI, Research Diagnostics, INC, Concord, MA, USA, RDI-S01005; concentrated 30ng/ml). Primary antibodies were incubated with their specific blocking peptides for $2 \mathrm{~h}$ at room temperature and then incubated with neuroblastoma tissues.

The reactions were observed with a Nikon Optiphot-2 light microscope and documented using a CCD camera (Baumer Optronic, arc6000c, Radeberg, Germany).

Finally, the analysis was performed blind on coded samples.

Quantitative and statistical analyses. Based on the immunohistochemical results, which were analysed through the use of Microimage (Olympus) morphometric software, the content of reaction-positive cells was determined by comparing the number of immunopositive cells with the total number of nucleated cells. Changes in antigen distribution were evaluated measuring the area of marker expression on each colour image by using the 'eye-dropper' tool as previously reported [21]. The estimates of CD34, VEGFR-2 and VEGF-C expressions were subjected to mathematical analysis in order to examine changes of these markers in study and control groups. These differences were then evaluated by a one-way analysis of variance test (ANOVA). To determine the significances between group means in the analysis of variance, the nearest significant difference test (Tukey test) was used as the multiple comparison analysis. Significance was set at $\mathrm{p}<0.05$ [32].

On the other hand, the Fisher's exact test, due to extremely limited number of patients, was employed to compare the frequencies of disease progressions and tumour related deaths in the VEGF-C positive and VEGF-C negative patients. Significance was defined at $\mathrm{p}<0.05$ [32].

\section{Results}

\section{Clinical observation}

During the observation period (the mean overall follow-up interval was 17 months) clinical progression (defined as radiological and histological confirmed local relapse of malignancy or the appearance of distant metastases) was noted in 12 children from the study group and 4 patients composing the control group (no distant metastases in these subjects). Twelve of them (10 allocated to study group and 2 of control group) died due to the direct effect of metastases (tumour related death). At the end of the observation period, 20 children were still alive.

\section{Immunohistochemical expressions of CD34, VEGFR-2 and VEGF-C in tumour tissue}

Consecutive slides incubated with anti-CD34 (Fig. 1a) and anti-VEGFR-2 (Fig. 1b) antibodies revealed that the two markers were co-localized. These immunopositive cells were situated exclusively within endothelial layer of the blood vessels located within tumour foci as well as among loosely arranged stromal cells. Interestingly, the same immunoreactivity and localisation was observed in all the stadium 4 (study group) and stadium 3 children (control group, $\mathrm{p}=0.97$, ns). Moreover, endothelial cells composing original (not angiogenic) blood vessels performed significantly lower expression of both CD34 and VEGFR-2 as compared to blood vessels (angiogenic) present within tumour foci $(p=0.003$ and $p=0.0056$ consequently). No CD133 expression was found within all studied specimens (data not shown).

According to VEGF-C expression, it was present in a single child qualified to stadium $3 \mathrm{NB}$ and in $15 / 18$ children from the study group. VEGF-C positive cells in these patients consisted exclusively of blasts; no VEGF-C expression was found in any of the endothelial cells (Fig. 1c and Fig. 2), nor within stromal cells (Fig. 1c).

Consecutive slides incubated with anti-VEGF-C and anti-CD34 or anti-VEGFR-2 antibodies revealed that the latter endothelial markers were situated in the closest proximity to VEGF-C immuno-positive aggregations of cancer cells (Fig. 1a-c). Additionally, blood vessels stained with CD34 and VEGFR-2 in stadium 4 patients, were significantly active angiogenic structures since tumour metastatic cells (expressing Ki67, Fig. 1d) were clearly visible within their lumen. Detailed information is present in Table 1.

Finally, the specific blocking peptides (data not shown) inhibited the staining described above. Identical results were obtained by using normal mouse IgG or PBS.

\section{Statistical analysis}

As demonstrated by Fisher's exact test (Table 2), the risk of NB treatment failure (progression or relapse) as well as tumour related death, when all the patients were considered (regardless of NB stage), was found to be significant in VEGF-C positive patients $(p=0.0061$ and $p=0.0003$ consequently). Comparatively, the risk of metastases was found to be significant in patients expressing VEGF-C in tumour blast cells $(p<0.0001)$. The expression of CD34 and VEGFR-2 by ECs had no prognostic value.

On the other hand, as shown in Table 2, the risk of neuroblastoma relapse or death was not significant, when stadium 3 or stadium 4 patients were considered separately (although the risk of tumour related death in stadium 4 patients could be regarded as nearly significant; $\mathrm{p}=0.0686$ )

Statistical analysis of those patients in whom no treatment failure was noted during the observation period revealed that the probability of NB remission was significantly higher in these study participants with VEGF-C -negative blasts $(\mathrm{p}=0.0061)$.

\section{Discussion}

It must be emphasized in particular that all the patients at the time of surgery had tumour tissue affected more 


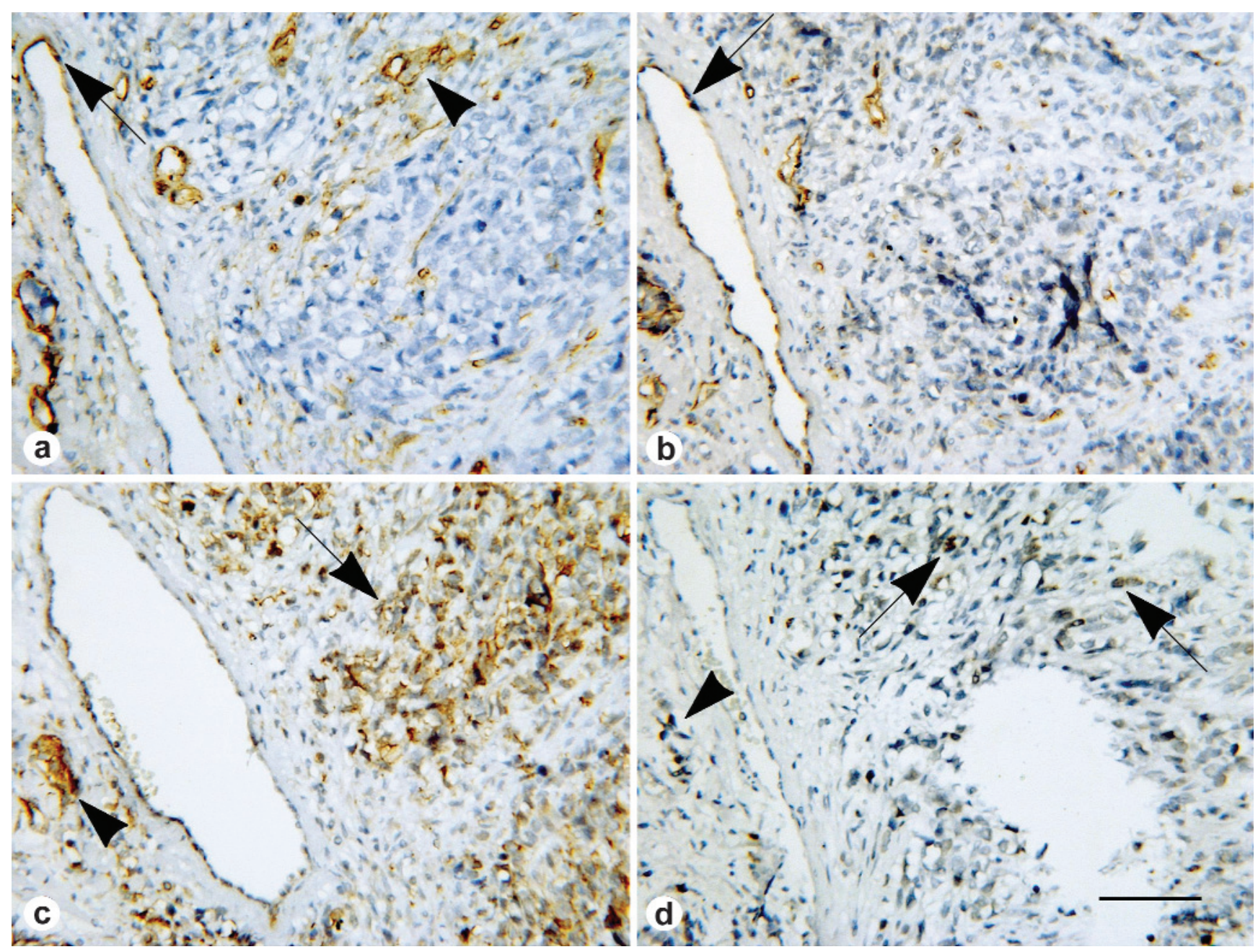

Fig. 1. Immunohistochemistry of CD34 (a), VEGFR-2 (b) and one of its ligand VEGF-C (c) as well as Ki67 (d) in neuroblastoma tumour of a 5-year old child. (a) CD34 positive ECs in blood vessels of stromal phase of the tumour (arrowhead) and a few CD34 positive ECs in a single vein of neuroblastoma stromal component (arrow). (b) consecutive slide incubated with anti-VEGFR-2 antibodies reveals that the two markers (CD34 and VEGFR-2) are co-localized; immunopositive cells are situated exclusively within endothelial layer of the blood vessels located within tumour foci as well as among loosely arranged stromal cells; notice a few VEGFR-2 positive ECs in a single vein of neuroblastoma stromal component (arrow). (c) VEGF-C immunoreactivity within tumour cells (arrow) and metastatic cells in angiogenic blood vessels (arrowhead); no VEGF-C expression is found in any of the ECs. (d) immunohistochemical reaction for Ki67 is present in tumour cells (arrows) and metastatic cells which are clearly visible within the lumen of angiogenic vessels (arrowhead). Scale bar: $100 \mu \mathrm{m}$.

or less by chemotherapy; however, this was the only way to obtain that time histological material. Naturally, it was not 'virgin' tissue, but there were still large areas of neoplastic tissue free of necrosis, haemorrhage or fibrosis, as can be seen in the provided pictures. In our opinion such a treatment primarily decreased tumour volume by reduction at the periphery and had less effect on the central portion from which all the tissue blocks were obtained.

The first observation related to the present study is that NB blood vasculature is mainly composed of late EPCs. These cells expressing both CD34 and VEGFR2 might facilitate tumour cells invasion into blood vessels when accompanied by extra-vascular secretion of VEGF-C.
CD34 - a proteoglycan found on endothelial and bone marrow cells belongs to the group of endothelial ligands which can bind L-selectin (CD62L). This type of selectin, expressed primarily on lymphocytes, serves as a homing receptor for leukocytes to cytokineactivated cells at sites of inflammation [33]. Physiologically endothelial cells express CD34 in lymphatic organs and post-capillary venules which initiate the process of diapedesis [34]. Our results highlight the presence of CD34 positive ECs in all the blood vessels of tumour stroma in all the neuroblastoma children (regardless of patients age and disease stage). CD34positive cells were most likely not present in endothelial cells of lymphatic vessels which must have been VEGFR-2 negative as referred to observation on con- 
Table 1. Clinical characteristics and results of CD34/VEGFR-2 and VEGF-C determination in children diagnosed with neuroblastoma.

\begin{tabular}{|c|c|c|c|c|c|c|}
\hline $\begin{array}{c}\text { Age } \\
\text { (years) }\end{array}$ & $\begin{array}{c}\text { No. of } \\
\text { patients }\end{array}$ & Stage* & $\begin{array}{c}\% \text { relapses } \\
\text { (no. of } \\
\text { patients) }\end{array}$ & $\begin{array}{c}\% \text { tumour related } \\
\text { death } \\
\text { (no. of patients) }\end{array}$ & $\begin{array}{c}\% \text { CD)34/VLGliR-2 positive } \\
\text { cases } \\
\text { (no. of patients) }\end{array}$ & $\begin{array}{c}\% \text { VLGi-C positive cases } \\
\text { (no. of patients) }\end{array}$ \\
\hline $3-16$ & 18 & 4 & $66.7(12)$ & $55.6(10)$ & $100(18)$ & $83.3(15)$ \\
\hline $3-17$ & 14 & 3 & $28.6(4)$ & $14.3(2)$ & $100(14)$ & $7.1(1)$ \\
\hline
\end{tabular}

*according to The International Neuroblastoma Staging System [12]; VEGFR - vascular endothelial growth factor receptor; VEGF-C - vascular endothelial growth factor $\mathrm{C}$

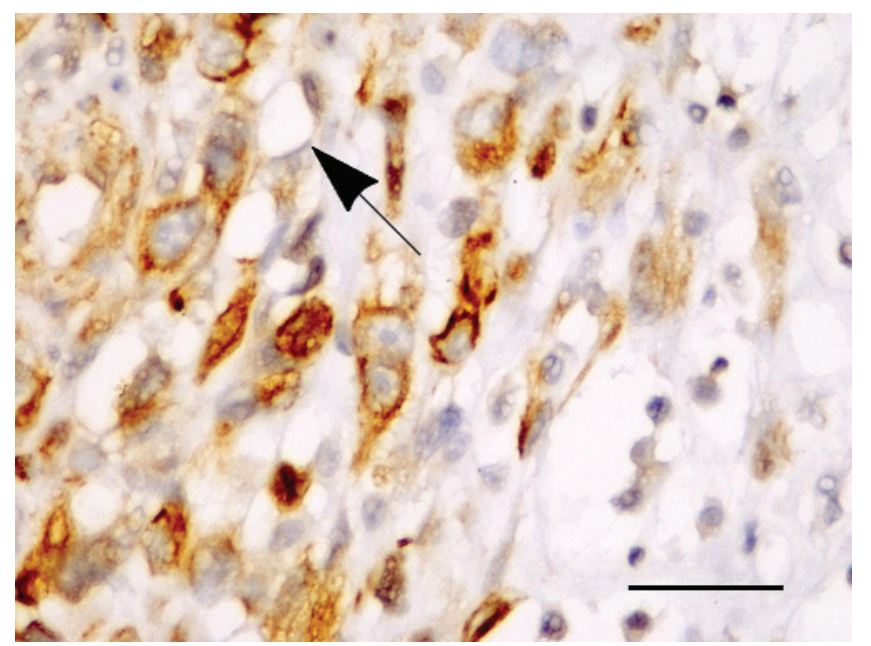

Fig. 2. Immunohistochemistry of VEGF-C in neuroblastoma tumour of a 4-year old child. Strong VEGF-C immunoreactivity is observed exclusively within cytoplasm of cancer cells. Microvessel bed of the tumour is VEGF-C negative (arrow). Scale bar: 50 $\mu \mathrm{m}$.

secutive slides. It is highly probable that CD34-positive ECs or EPCs at sites of neoplastic tissues empower cancer cells to cross the wall of the blood vessels. It was not yet clear, however, what is the trigger mechanism for this process. In our opinion it could be explained in part by the presence of VEGFR-2 in EPCs and one of its ligand - VEGF-C in tumour cells.

VEGFR-2 binds VEGF, VEGF-C and VEGF-D [27]. Although the binding affinity of VEGF towards VEGFR-2 is lower than that for VEGFR-1, selective activation of VEGFR-1 and VEGFR-2 has shown that VEGFR-2 is the primary receptor transmitting VEGF and VEGF-C signals in endothelial cells [35-37]. The expression of VEGFR-2 is autoregulated: VEGF, VEGF$\mathrm{C}$ and VEGF-D up-regulate the expression of VEGFR-2 $[38,39]$. VEGFR-2 expression is down-regulated in the adult blood vascular ECs, and is again up-regulated in the endothelium of angiogenic blood vessels [40].

The mature form of VEGF-C induces mitogenesis, migration and survival of ECs [41]. During development, VEGF-C is expressed along with its receptor VEGFR-3 predominantly in regions where lymphatic vessels develop $[42,43]$. The expression then decreases in most tissues, remaining high in the lymph nodes [44].
Table 2. Correlation between treatment failure (relapse). tumour related death and VEGF-C expression in cancer cells of children with neuroblastoma (Fisher's exact test).

\begin{tabular}{|c|c|c|}
\hline \multirow{2}{*}{ Stage $*$} & \multicolumn{2}{|c|}{ Correlation of VF(GF-C positive pattern to } \\
\cline { 2 - 3 } & $\begin{array}{c}\text { disease relapse } \\
\text { (p valuc) }\end{array}$ & $\begin{array}{c}\text { tumour related death } \\
\text { (p valuc) }\end{array}$ \\
\hline 4 & 0.2451 & 0.6860 \\
\hline 3 & 0.2857 & 0.1429 \\
\hline$\Sigma(4+3)$ & 0.0061 & 0.0003 \\
\hline
\end{tabular}

*according to The International Neuroblastoma Staging System [12]; VEGF-C = vascular endothelial growth factor $\mathrm{C}$; ( $\mathrm{p}$ value) statistically significant if $<0.05$.

Recently VEGF-C has been reported to play a crucial role in the regulation of lymphangiogenesis in human neuroblastoma [26]. It did not act as a factor promoting tumour blast cells growth but cooperated in development of VEGFR-3 positive lymphatic vessels. This study suit our observation in which we have not detected VEGFR-2 expression in cancer cells. We have evaluated, however, the presence of VEGFR-2 positive angiogenic blood vessels which, undoubtedly together with lymphatic vessels, compose the metastatic capacity of NB. As shown on Fig. 1d, these angiogenic blood vessels are metastatically active structures since Ki67 positive tumour cells were clearly visible inside their lumen.

Although VEGF-C is not essential for the development of blood vessels unlike its receptor VEGFR-2, it is a common factor which combine angio- and lymphangiogenesis as well as recruiting EPCs from the bone marrow (30\% homology to VEGF165). In a few experimental models, tumour cells overexpressing VEGF-C or VEGF-D induced peritumoural and in some cases stromal lymphangiogenesis and tumour cell invasion into lymphatic vessels $[40,45,46]$. Interestingly, also some recently published data indicate that NBassociated endothelial microvessels can originate directly from tumour cells [47]. In our observation, the similar VEGF-C related activity could be present also in angiogenic NB blood vessels. VEGF-C which is released in the closest proximity of these blood vessels not only contributes in endothelial growth but also 
probably enables its activation promoting CD34dependent diapedesis of cancer cells. The process of aggressive chemotherapy may then lead not only to eradication of tumour cells but also to reducing of bone marrow progenitor cells. The former impact of bone marrow is definitely the undesirable side effect but the latter one may result in reduction of EPCs and, in fact, extenuation of tumour vascular potency. From this point of view, the restriction of chemotherapy regimen postulated recently in NB should be accompanied by parallel anti-angiogenic treatment directed against VEGFR-2.

The second observation in this research involves VEGF-C potency as a facultative risk factor in this disease. NB growth, as in all tumours larger than 1-2 $\mathrm{mm}$, is strictly dependent on angiogenesis $[7,48]$. Up to the present, the greatest attention in NB has been directed at VEGF as well as its receptors VEGFR-1 and VEGFR-2 [49]. Still, there are few reports describing the expression of VEGF-C in neuroblastoma tissue [26].

In our findings VEGF-C was expressed by all cancer cells in 15/18 children qualified to stadium 4 NB and only in a single patient from the control group (stadium 3). It may suggest that in spite of EPCs potency in angiogenic NB blood vasculature it is VEGF-C which independently triggers tumour cells invasion into blood vessels. Thus it should be regarded as a novel risk factor. In our preliminary, not-published yet studies, we found that VEGF-C is also present in microscopically normal bone marrow hematopoietic cells in stadium $3 \mathrm{NB}$. It seems that these cells are involved in early phase of homing the metastatic cells in the bone marrow. In that way VEGF-C would be engaged not only into formation of metastases at site of tumour but also in their incorporation within distant tissues.

In conclusion, VEGF-C expression in neuroblastoma might constitute a novel risk factor and could direct future anti-angiogenic treatment strategy. The proximity of VEGF-C and CD34/VEGFR-2 in blast cells and endothelial components of neuroblastoma could be the equivalent of a potentially interesting VEGF-C fashion involving a tumour cell invasion into the blood vessels in an early phase of metastases promoting.

Acknowledgments: The authors thank Prof. K. C. Gatter (University of Oxford, UK) for the generous donation of the VEGFR-2 antibodies, Professor G. Shaw for his language editing and Mrs S. Bramke (Anatomy Department, Technical University in Dresden, Germany) for her excellent immunohistochemical work.

\section{References}

[ 1] Hristov M, Weber C. Endothelial progenitor cells: characterization, pathophysiology, and possible clinical relevance. J Cell Mol Med. 2004;8:498-508.
[ 2] Asahara T, Murohara T, Sullivan A et al. Isolation of putative progenitor endothelial cells for angiogenesis. Science. 1997; 275:964-967.

[3] Peichev M, Naiyer AJ, Pereira D et al. Expression of VEGFR-2 and AC133 by circulating human CD34+ cells identifies a population of functional endothelial precursors. Blood. 2000;95:952-958.

[4] Gehling UM, Ergün S, Schumacher U et al. in vitro differentiation of endothelial cells from AC133-positive progenitor cells. Blood. 2000;95:3106-3112.

[5] Quirici N, Soligo D, Caneva L et al. Differentiation and expansion of endothelial cells from human bone marrow CD133+ cells. Br J Haematol. 2001;115:186-194.

[6] Hristov M, Erl W, Weber PC. Endothelial progenitor cells: mobilization, differentiation, and homing. Arterioscler Thromb Vasc Biol. 2003;23:1185-1189.

[ 7] Ostalska-Nowicka D, Zachwieja J, Nowicki M et al. Vascular endothelial growth factor (VEGF-C1)-dependent inflammatory response of podocytes in nephrotic syndrome glomerulopathies in children: an immunohistochemical approach. Histopathology. 2005;46:176-183.

[ 8] Folkman J. What is the evidence that tumours are angiogenesis dependent? J Natl Cancer Inst. 1990;82;4-6.

[9] Maitra A, Kumar V. Diseases of Infancy and Childhood. In: Robbins and Cotran Pathologic Basis of Disease (7/e by Kumar, Abbas, Fausto). Philadelphia: Elsevier Sanders, 2005, pp. 500-504.

[10] Shimada H, Ambros IM, Dehner LP et al. Terminology and morphologic criteria of neuroblastic tumors: recommendations by the International Neuroblastoma Pathology Committee. Cancer. 1999;86:349-363.

[11] Bomken SN, Redfern K, Wood KM et al. Limitations in the ability of NB84 to detect metastatic neuroblastoma cells in bone marrow. J Clin Pathol. 2006;59:927-929.

[12] Castel V, García-Miguel P, Canete A et al. Prospective evaluation of the International Neuroblastoma Staging System (INSS) and the International Neuroblastoma Response Criteria (INRC) in a multicentre setting. Eur J Cancer. 1999;35(4): 606-611.

[13] Burchill SA. Micrometastases in neuroblastoma: are they clinically important? J Clin Pathol. 2004;57:14-20.

[14] Reid MM. Minimal metastatic disease. J Clin Pathol. 2004; 57:21.

[15] Shimada H, Ambros IM, Dehner LP et al. The International Neuroblastoma Pathology Classification (the Shimada system). Cancer. 1999;86:364-372.

[16] Bown N. Neuroblastoma tumour genetics: clinical and biological aspects. J Clin Pathol. 2001;54:897-910.

[17] Lastowska M, Cotterill S, Bown N et al. Breakpoint position on $17 \mathrm{q}$ identifies the most aggressive neuroblastoma tumors. Genes Chromosomes Cancer. 2002;34:428-436.

[18] Pession A, Tonelli R. The MYCN oncogene as a specific and selective drug target for peripheral and central nervous system tumors. Curr Cancer Drug Targets. 2005;5:273-283.

[19] Nakagawara A, Arima-Nakagawara M, Scavarda NJ et al. Association between high levels of expression of the TRK gene and favorable autcome in human neuroblastoma. $N$ Engl J Med. 1993;328:847-854.

[20] Nowicki M, Ostalska-Nowicka D, Miskowiak B. Prognostic value of stage IV neuroblastoma metastatic immunophenotype in the bone marrow: preliminary report. J Clin Pathol. 2006;59:150-152.

[21] Nowicki M, Miskowiak B. Comparison of the cell immunophenotype of metastatic and primary foci in stage IV-S neuroblastoma. Folia Histochem Cytobiol. 2002;40:297-303.

[22] Korja M, Finne J, Salmi TT et al. No GIST-type c-kit gain of function mutations in neuroblastic tumours. J Clin Pathol. 2005;58:762-765. 
[23] Meitar D, Crawford SE, Rademaker AW et al. Tumor angiogenesis correlates with metastatic disease, N-myc amplification, and poor outcome in human neuroblastoma. J Clin Oncol. 1996;14:405-414.

[24] Rossler J, Breit S, Havers W et al. Vascular endothelial growth factor expression in human neuroblastoma: up-regulation by hypoxia. Int $J$ Cancer. 1999;81:113-117.

[25] Pavlakovic H, Rossler S von VJ, Koscielniak E et al. Quantification of angiogenesis stimulators in children with solid malignancies. Int J Cancer. 2001;92:756-760.

[26] Lagodny J, Jüttner E, Kayser G et al. Lymphangiogenesis and its regulation in human neuroblastoma. Biochem Biophys Res Commun. 2007;12:571-577.

[27] Tammela T, Enholm B, Alitalo K et al. The biology of vascular endothelial growth factors. Cardiovasc Res. 2005;65:550563.

[28] Kaneko M, Nishihira H, Mugishima $\mathrm{H}$ et al. Stratification of treatment of stage 4 neuroblastoma patients based on N-myc amplification status. Study Group of Japan for Treatment of Advanced Neuroblastoma, Tokyo, Japan. Med Pediatr Oncol. 1998;31:1-7.

[29] Pillai G, Cook N, Turley H, et al. The expression and cellular localization of phosphorylated VEGFR2 in lymphoma and non-neoplastic lymphadenopathy: an immunohistochemical study. Histopathology. 2005;46:209-216.

[30] Pileri SA, Roncador G, Ceccarelli C. Antigen retrieval techniques in immunohistochemistry: comparison of different methods. J Pathol. 1997;183:116-123.

[31] Shi SR, Cote RJ, Taylor CR. Antigen retrieval immunohistochemistry: past, present and future. J Histochem Cytochem. 1997;45:327-343.

[32] Armitage P. Statistical methods in medical investigations (in Polish), 1st edn. Warszawa: PZWL 1978, pp. 97-103.

[33] Chabannon C. [Happy birthday, CD34!] Med Sci (Paris). 2005;21:503-506.

[34] Mineo TC, Ambrogi V, Baldi A et al. Prognostic impact of VEGF, CD31, CD34, and CD105 expression and tumour vessel invasion after radical surgery for IB-IIA non-small cell lung cancer. J Clin Pathol. 2004;57:591-597.

[35] Meyer M, Clauss M, Lepple-Wienhues A et al. A novel vascular endothelial growth factor encoded by Orf virus, VEGF$\mathrm{E}$, mediates angiogenesis via signalling through VEGFR-2 (KDR) but not VEGFR-1 (Flt-1) receptor tyrosine kinases. EMBO J. 1999;18:363-374.

[36] Wise LM, Veikkola T, Mercer AA et al. The vascular endothelial growth factor (VEGF)-like protein from orf virus NZ2 binds to VEGFR2 and neuropilin-1. Proc Natl Acad Sci USA. 1999;96:3071-3076.
[37] Gille H, Kowalski J, Li B et al. Analysis of biological effects and signalling properties of Flt-1 (VEGFR-1) and KDR (VEGFR-2). A reassessment using novel receptor-specific vascular endothelial growth factor mutants. $J$ Biol Chem. 2001;276:3222-3230.

[38] Stacker SA, Caesar C, Baldwin ME et al. VEGF-D promotes the metastatic spread of tumor cells via the lymphatics. Nat Med. 2001;7:186-191

[39] Shima DT, Deutsch U, D'Amore PA. Hypoxic induction of vascular endothelial growth factor (VEGF) in human epithelial cells is mediated by increases in mRNA stability. FEBS Lett. 1995;370:203-208

[40] Partanen TA, Alitalo K, Miettinen M. Lack of lymphatic vascular specificity of vascular endothelial growth factor receptor 3 in 185 vascular tumors. Cancer. 1999;86:2406-2412.

[41] Saharinen P, Tammela T, Karkkainen MJ et al. Lymphatic vasculature: development, molecular regulation and role in tumor metastasis and inflammation. Trends Immunol. 2004; 25:387-395

[42] Karkkainen MJ, Haiko P, Sainio K et al. Vascular endothelial growth factor $\mathrm{C}$ is required for sprouting of the first lymphatic vessels from embryonic veins. Nat Immunol. 2004;5:74-80.

[43] Kukk E, Lymboussaki A, Taira S et al. VEGF-C receptor binding and pattern of expression with VEGFR-3 suggests a role in lymphatic vascular development. Development. 1996; 122:3829-3837.

[44] Lymboussaki A, Olofsson B, Eriksson U et al. Vascular endothelial growth factor (VEGF) and VEGF-C show overlapping binding sites in embryonic endothelia and distinct sites in differentiated adult endothelia. Circ Res. 1999;85: 992-999.

[45] Skobe M, Hawighorst T, Jackson DG et al. Induction of tumor lymphangiogenesis by VEGF-C promotes breast cancer metastasis. Nat Med. 2001;7:192-198.

[46] Karpanen T, Alitalo K. Lymphatic vessels as targets of tumor therapy? J Exp Med. 2001;194:F37-42.

[47] Pezzolo A, Parodi F, Corrias MV et al. Tumor origin of endothelial cells in human neuroblastoma. J Clin Oncol. 2007;25:376-383.

[48] Nowicki M, Ostalska-Nowicka D, Kaczmarek M et al. The significance of VEGF-C/VEGFR-2 interaction in the neovascularization and prognosis of nephroblastoma (Wilms' tumour). Histopathology. 2007;50:358-364.

[49] Komuro H, Kaneko S, Kaneko M et al. Expression of angiogenic factors and tumor progression in human neuroblastoma. J Cancer Res Clin Oncol. 2001;127:739-743

Submitted: 5 May, 2008 Accepted after reviews: 16 August, 2008 